\title{
Network Position and Crowdsourcing Innovation Contribution Behavior: The Moderating Role of Knowledge Absorption Capacity
}

\author{
Qingliang Meng $\mathbb{D}$, Yi Hang $\mathbb{D}$, and Xiaojun Chen \\ School of Management \& Economics, Jiangsu University of Science and Technology, 301 Xuefu Road, Zhenjiang 212013, \\ Jiangsu, China \\ Correspondence should be addressed to Qingliang Meng; mengzhi007@163.com
}

Received 19 March 2021; Accepted 30 November 2021; Published 30 December 2021

Academic Editor: Atila Bueno

Copyright (C) 2021 Qingliang Meng et al. This is an open access article distributed under the Creative Commons Attribution License, which permits unrestricted use, distribution, and reproduction in any medium, provided the original work is properly cited.

\begin{abstract}
Purpose. The purpose of this study is to examine the relationship between network position and crowdsourcing innovation contribution behavior and the moderating effects of knowledge absorption capacity on the aforementioned relationship. Design/Methodology/Approach. Focusing on the Chinese context, the study conducts empirical research with the user's knowledge-sharing network of the MIUI community to test the research model. The negative binomial regression model which is suitable for processing discrete data is used to examine the main effects of the network position, knowledge absorption capacity, and crowdsourcing innovation contribution behavior. Findings. The findings reveal that the closer the user gets to the center of the network, the more likely they will contribute. The users' knowledge absorption capacity can help stimulate the users' crowdsourcing innovation contribution behavior, and the users with stronger knowledge absorption capacity are more likely to transform their network position advantages into innovative contribution behaviors. Practical Implications. The study provides evidence that network position has a positive impact on their crowdsourcing innovation contribution behavior, and knowledge absorption capacity promotes the crowdsourcing innovation behavior of users. Managers should encourage users to occupy a favorable network position and increase knowledge exchange with other users, while at the same time continuously improving their own knowledge absorption capacity. Originality/Value. This study combines social network theory and the individual mindset to introduce knowledge absorptive capacity into the relationship model of the user's network position and crowdsourcing innovation contribution behavior, thereby constructing a complete path of "knowledge supply-knowledge acquisition-knowledge application-knowledge output." The study contributes to provide a theoretical basis for an in-depth understanding of the influence relationship between network position and crowdsourcing innovation contribution behavior. Also, it provides a reference for enterprises to carry out practical crowdsourcing innovation community governance and improve innovation performance.
\end{abstract}

\section{Introduction}

Crowdsourcing innovation refers to the business model in which enterprises transfer the traditional innovation tasks performed by internal employees in a free and voluntary manner to external network users (the public) [1]. This model has been proved to be a significant innovation model for acquiring knowledge from external networks [2]. For example, with the help of InnoCentive, $P \& G$ 's innovative community has increased the proportion of innovation outside the company from $15 \%$ to $50 \%$, and the R\&D capacity is increased by $60 \%$; up to date, more than 28,577 ideas have been submitted on the IdeaStorm crowdsourcing community created by Dell, and more than 550 public of that have been implemented; relying on My StarbucksIdea.com crowdsourcing innovation community, Starbucks continuously collect external mass ideas and promote brand awareness. In return, it gets the product and service 
innovation concept; to solve the AIDS reverse transcriptase structural puzzle that has plagued the scientists for fifteen years, Foldit relies on the whole network players' power and success. Crowdsourcing innovation is profoundly affecting the current enterprise innovation model. More and more enterprises are beginning to establish different crowdsourcing innovation models.

The modern innovation model has gradually shifted from the "closed-door" mode to the crowdsourcing model of seeking cooperation at various stages. Therefore, innovation is also a process of forming an interactive network of collaborative innovation [3]. Scholars who support network theory believe that individuals who occupy a favorable network position in the innovation interaction network are more likely to improve their innovation performance $[4,5]$. Although a large number of scholars have tested and verified this theory through empirical research $[6,7]$, scholars who support the individual mindset believe that network theory pays too much attention to the influence of personal external connections on innovation performance and ignores the difference in the ability of individuals to absorb external knowledge (Giuliani, 2005; [8, 9]). According to the "inputprocess-output" model (IPO), to achieve the purpose of innovation, individuals need to acquire and apply the external knowledge to realize the integration of external resources and existing resources [10]. These scholars believe that the individual's ability to absorb external knowledge is heterogeneous. And the difference between individual's knowledge absorption capacities is the critical factor affecting innovation performance. Zahra and George [8] pointed out that individuals who can effectively acquire and apply knowledge have better innovation performance and can obtain more significant competitive advantages. Stenberg and Arndt [9] even believe that the individual's knowledge absorptive capacity can affect innovation performance more than external relationships.

Based on integrating the views of both parties, scholars combine the individual's external network position with internal knowledge absorption capacity to study their impact on innovation. Tsai [11] first verified that the degree centrality and absorptive capacity have an important impact on enterprises' innovation performance. But his research only considers the degree centrality without considering other network position indicators such as structural holes. And he simply uses $R \& D$ revenue to measure the knowledge absorptive capacity of an enterprise, without an in-depth analysis of the impact of various dimensions of absorptive capacity on innovation. After that, many scholars have successively carried out research [12-14]. But since the research on network structure is still in the qualitative description stage, scholars mostly focus on the impact of knowledge absorptive capacity on innovation performance. In recent years, Qian et al. [3] studied the effect of knowledge absorptive capacity as a moderating factor on the relationship between corporate network position and corporate innovation performance. But their research mainly concentrated on the enterprise level and ignored the relationship between network position, knowledge absorption capacity, and innovation contribution behavior from the individual level.
Basically, the research question of the paper is the following: each user plays a different role in the crowdsourced innovative virtual community [15]. Their interaction behavior and network positions are quite heterogeneous; whether the user's network position still has a significant impact on their innovation contribution behavior? And how does the user's knowledge absorption capacity affect their crowdsourcing innovation contribution behavior? Thus, the main aim of this research is to examine mechanisms and paths of user's network position on their innovation contribution behavior and the mediating role of knowledge absorption capacity. In other words, few scholars have conducted research from the individual level and hence less well understood in academic research and also in industry practice. This is the main theoretical highlight of this research along with its involvement with the managerial practice.

To achieve the above aim, the paper is structured as follows. Section 2 introduces the theories of social network analysis and individual mindset and defines the concept of user's contribution behavior of crowdsourcing innovation. Section 3 makes assumptions about the relationship between network position, innovation contribution behavior, and knowledge absorption capacity and constructs theoretical models. Section 4 explains the source of the data and the measurement of each research variable. In Section 5, the results of each hypothesis test are shown. In Section 6, the implications are presented and discussed. Eventually, in Section 7, the contributions and some limitations of the paper are drawn.

\section{Basic Theory and Construct Definition}

2.1. User Contribution Behavior of Crowdsourcing Innovation. The crowdsourcing innovation community's original intention to open user communication is to facilitate users to spontaneously conduct interactive communication around a certain product or function, promote knowledge sharing, and stimulate users' innovative contribution behavior. However, different users' needs and behaviors are heterogeneous, so different users have different contribution behaviors. According to users' initiative to post information [16-18], the user's contribution behavior is divided into proactive contribution and responsive contribution. The user's proactive contribution behavior is manifested in that the user actively submits incremental knowledge, which is different from previous experience. And the user's responsive contribution refers to the user commenting on other users' topics or answering other users' questions, which will continuously increase the community information circulation and the awareness of topics. Qin et al. [18] further defined the connotation of active contribution behavior and reactive contribution behavior and developed a measurement scale for two kinds of contribution behavior.

According to the connotation of user's contribution behavior and the characteristics of the crowdsourcing innovation community, this article defines two types of user's contribution behavior as follows: proactive contribution behavior refers to users actively sharing knowledge, 
proposing ideas, or product improvement suggestions, etc., to obtain official or other users' approbation; responsive contribution behavior refers to the behavior of users answering other users' questions or expressing evaluations and suggestions on other users' opinions.

2.2. Social Network Analysis. SNA is a set of norms for qualitative research and quantitative discussion of social relationship structures and their attributes. It has the advantage of being able to analyze networks with multiple nodes and multiple subjects. The social network analysis method consists of nodes and connections, where nodes represent the actors in the event, and connections represent the relationship between them. SNA is a method of studying the dynamic relationship between multiple entities, forming a relationship network diagram. SNA mainly analyzes the characteristics of the relationship network structure from the out-degree, in-degree, clique, and centrality. It can also analyze and explore the whole network from overall network structure visualization, network density, and small-world effect.

2.3. The Individual Mindset. Dweck [19] points out that the individual mindset is the implicit belief of the individual about his own ability. The individuals have two different implicit beliefs about self-reliance. One is the incremental theory, and the other is the entity theory. The individuals who support the incremental theory believe that their abilities can be improved through accomplishing hard work. So this type of individual tends to set higher learning goals and regards difficult tasks to improve their abilities. The individuals who support the entity theory believe that the ability is innate and cannot be changed, so they tend to pursue achievement goals and avoid tasks that may fail.

\section{Research Hypothesis}

3.1. User's Network Position and Crowdsourcing Innovation Contribution Behavior. The user's network position is the result of the user's connection in the process of information interaction, which is an important research object of network theory. In the information interaction network, the user's network position is related to their ability to acquire/ spread knowledge and seek cooperation, which affects their contribution behavior [11]. In social network analysis, there are many indicators to describe network position, but in innovation performance research, scholars usually take the centrality to reflect the power and the structural holes as individual network position measurement indicators $[3,20,21]$. In social network theory, there are a large number of indicators to measure the importance of individuals, such as degree centrality, betweenness centrality, closeness centrality, eigenvector centrality, and structural hole. But each indicator has its own emphasis. In the past, scholars often only chose closeness centrality and structural hole to describe individual network positions, ignoring the degree centrality which characterizes the scale of individual networks, the eigenvector centrality which characterizes the importance of nodes, and the limitation of the use of close centrality (the meaning of betweenness centrality is consistent with the meaning of structural holes). Therefore, this article further subdivides the specific meaning of the centrality and selects the degree centrality, eigenvector centrality, and structural hole to describe the network position of the node. Therefore, the following hypothesis is made.

$\mathrm{H}_{1}$ : the user's network position has a positive impact on his/her crowdsourcing innovation contribution behavior

3.1.1. The Impacts between the Degree Centrality and Crowdsourcing Innovation Contribution Behavior. In social network analysis, the degree centrality refers to the direct relationship between a node and other nodes, which is an important indicator to measure the size of the individual network. Generally speaking, users with a high degree centrality are at the core of the interactive network, and users with a small degree centrality are at the edge of the interactive network. The advantages of users with a high degree centrality in innovation are mainly as follows: first, these users have multiple knowledge acquisition channels and knowledge sources. When the scale of an individual's interactive network is larger, more sources of knowledge are included. The user will be easier to obtain knowledge released by other users, thereby promoting the combination of user knowledge and external knowledge to achieve innovation $[22,23]$. Secondly, due to having a large number of direct connections, these users have higher accessibility to disseminate knowledge, which is conducive to improving the overall user's knowledge availability. Besides, the higher degree centrality, the more appealing users will be in the innovation process. While individuals have a large number of knowledge sources, they also have a high degree of "exposure." When a user with a high degree centrality needs new knowledge, because of his high exposure, the possibility of obtaining accurate and effective knowledge is increased; on the other hand, when other users need help, the user with high degree centrality uses his influence to expand the scope of information transmission to obtain solutions [3]. Therefore, the following hypotheses are made:

$\mathrm{H}_{1 \mathrm{a}}$ : the user's degree centrality has a positive impact on his/her proactive contribution behavior

$\mathrm{H}_{1 \mathrm{~b}}$ : the user's degree centrality has a positive impact on his/her responsive contribution behavior

3.1.2. The Impacts between the Eigenvector Centrality and Crowdsourcing Innovation Contribution Behavior. The eigenvector centrality characterizes the importance of a node in the network and reflects the quality of a node's connection. Scholars who support network theory point out that the importance of a node to the overall network depends not only on the number of nodes directly connected to it but also on the importance of the nodes directly connected to it $[24,25]$. Generally speaking, the eigenvector centrality of a node is positively correlated with the eigenvector centrality 
of adjacent nodes [26]. Users with high eigenvector centrality often have the following advantages: first, the higher the eigenvector centrality of the users is, the more important the connected user will be. These users will have more opportunities to obtain the key knowledge to innovation. Second, although users with a high degree centrality have a wide range of news sources, valuable knowledge is often hidden in a huge flow of information, requiring a lot of human resources and material resources to identify. Compared with them, users with a high eigenvector centrality tend to have more reliable information sources, which can help reduce the cost of knowledge search and increase the possibility of stimulating innovation. Therefore, the following hypotheses are made:

$\mathrm{H}_{1 c}$ : the user's eigenvector centrality has a positive impact on his/her proactive contribution behavior

$\mathrm{H}_{1 \mathrm{~d}}$ : the user's eigenvector centrality has a positive impact on his/her responsive contribution behavior

\subsubsection{The Impacts between the Structural Hole and Crowd-} sourcing Innovation Contribution Behavior. Structural holes are a missing relationship that prevents information flow. The amount of structural holes occupied by users reflects users' ability to control the interactive network [27]. Users occupying structural holes can have information control advantages by connecting two users who are not directly connected. Zaheer and Bell [28] pointed out that the user's ability to acquire knowledge resources is affected by the network position, and occupying an advantageous position is conducive to innovation activities. First, users who occupy structural holes can efficiently acquire knowledge and control the direction of knowledge circulation, thereby maintaining their innovative advantages. Secondly, users in structural holes have nonredundant heterogeneous connections, which help to acquire knowledge in different fields. This promotes the integration of new and old knowledge to complete innovation. Thirdly, because the user occupying the structural hole connects two users who are not directly connected, the degree of interconnection of the interactive network is improved, and the possibility of missing knowledge transmission is effectively reduced. Therefore, the following hypotheses are made:
$\mathrm{H}_{1 \mathrm{e}}$ : the user's structural hole has a positive impact on his/her proactive contribution behavior
$\mathrm{H}_{1 \mathrm{f}}$ : the user's structural hole has a positive impact on his/her responsive contribution behavior

\subsection{User's Knowledge Absorption Capacity and Crowd- sourcing Innovation Contribution Behavior. In the last century, some scholars proposed that most of the innova- tions did not originate from "original creation" but from "borrowing creation" [29]. The diversity and exposure of external knowledge sources have an important impact on the knowledge dissemination of the crowdsourcing innovation community and also play an important role in the effective knowledge acquisition and integrated utilization of}

knowledge seekers. Martinez believes that the crowdsourcing innovation model is based on the perception that the crowd is smarter than the elites. That is to say, it can create more innovative and valuable solutions through the integration of the crowd's wisdom and skills distributed in different fields, different backgrounds, and different expertise. In the crowdsourcing innovation community, the user's knowledge absorption capacity can be divided into knowledge acquisition capacity and knowledge application capacity. Therefore, the following hypothesis is made:

$\mathrm{H}_{2}$ : the user's knowledge absorption capacity has a positive impact on his/her crowdsourcing innovation contribution behavior

\subsubsection{The Impacts between Knowledge Acquisition Capacity} and Crowdsourcing Innovation Contribution Behavior. The knowledge acquisition capacity refers to the subject's ability to identify and acquire valuable knowledge from the huge external knowledge [11]. The user's knowledge acquisition capacity mainly promotes their contribution behavior from two aspects: on the one hand, the user with stronger knowledge acquisition capacity, the higher the efficiency of the accumulation of knowledge, thereby improving the user's knowledge linkage capacity to stimulate their innovation contribution behavior; on the other hand, during the progress of acquiring knowledge, users can better understand the frontiers of community crowdsourcing innovation and the current needs of enterprises and increase their response rate on innovation, thereby strengthening their willingness to innovate and inspiring their innovative behavior. Based on this, the following hypotheses are proposed:

$\mathrm{H}_{2 \mathrm{a}}$ : the user's knowledge acquisition capacity has a positive impact on his/her proactive contribution

$\mathrm{H}_{2 \mathrm{~b}}$ : the user's knowledge acquisition capacity has a positive influence on his/her responsive contribution

3.2.2. The Impacts between Knowledge Application Capacity and Crowdsourcing Innovation Contribution Behavior. Knowledge application capacity refers to the subject's ability to digest the acquired external knowledge and combine it with its own existing knowledge to generate a new knowledge structure and then carry out practical application innovation [11]. After users digest the acquired external knowledge, the external knowledge becomes part of their own knowledge structure. However, the realization of innovation needs users to apply new knowledge through experiments, design, and other activities. Zahra believes that the knowledge application capacity can prompt the subject to complete the transformation of the absorbed knowledge into actual innovation. Scholars generally believe that the generation of an innovation or the proposal of an idea is the specific manifestation of the subject's knowledge application capacity. Therefore, this article believes that the user's knowledge application capacity mainly affects their proactive contribution behavior [3, 30,31]. Based on this, the following hypothesis is proposed: 
$\mathrm{H}_{2 \mathrm{c}}$ : the user's knowledge application capacity has a positive impact on his/her proactive contribution

\subsection{User's Network Position and Knowledge Absorptive} Capacity. Existing studies have confirmed that the knowledge sharing and knowledge spillover of collaborative innovation networks provide individuals with opportunities to obtain knowledge resources and provide support for individual's innovation at the same time [32]. Koka and Prescott [33] pointed out that the pros and cons of network position have a significant impact on the improvement of individual's knowledge acquisition and application capacity. Users with a high degree centrality, on the one hand, have a large number of information sources and information channels to obtain valuable knowledge, and their knowledge acquisition capacity is improved due to their dominant network position. On the other hand, frequent interaction between users promotes the integration of knowledge and the stimulation of innovation inspiration, promoting the improvement of users' knowledge application capacity. Users occupy a large number of structural holes to strengthen the control of the flow of knowledge resources. It means that the possibility of acquiring high-value knowledge is increased. And the possibility of bringing together different users to form knowledge and skills complementary is also increased, thereby improving their knowledge acquisition capacity and knowledge application capacity. The main reason why some users have high eigenvector centrality is that these users want to acquire high-quality knowledge and understand the frontiers of innovation for the first time, and they follow with a large number of key users in the community. Therefore, eigenvector centrality mainly affects the user's knowledge acquisition capacity. Thus, the following hypotheses are proposed:

$\mathrm{H}_{3}$ : the user's network position has a positive impact on his/her knowledge absorption capacity

$\mathrm{H}_{3 \mathrm{a}}$ : the user's degree centrality has a positive impact on his/her knowledge acquisition capacity

$\mathrm{H}_{3 \mathrm{~b}}$ : the user's eigenvector centrality has a positive impact on his/her knowledge acquisition capacity

$\mathrm{H}_{3 \mathrm{c}}$ : the user's structural hole has a positive impact on his/her knowledge acquisition capacity

$\mathrm{H}_{3 \mathrm{~d}}$ : the user's degree centrality has a positive impact on his/her knowledge application capacity

$\mathrm{H}_{3 \mathrm{e}}$ : the user's structural hole has a positive impact on his/her knowledge application capacity

\subsection{The Mediating Effect of Knowledge Absorptive Capacity.} The theoretical analysis of the above hypothesis shows that although users occupying favorable network positions have the advantage of obtaining external incremental information, the influence of users' network positions on contribution behavior is also related to the users' own knowledge absorption capacity. Escribano pointed out that the individual's knowledge absorptive capacity positively affects the ability to obtain benefits from external knowledge. In addition, a large number of scholars have proposed that it is necessary to incorporate knowledge absorptive capacity as a mediator into the research framework of the impact of network location on innovation [34-37]. Therefore, the following hypothesis is made:

$\mathrm{H}_{4}$ : the user's knowledge absorption capacity plays an intermediary role between network position and crowdsourced innovation contribution behavior

\subsubsection{The Mediating Effect of Knowledge Acquisition} Capacity. It is absolute that knowledge acquisition capacity can promote user's contribution behavior. A strong knowledge acquisition capacity can undoubtedly broaden the breadth of users' knowledge, stimulate the potential of users' knowledge connection, and promote users' contribution behavior. At the same time, the user's knowledge acquisition is an initiative behavior. Therefore, the strength of the user's knowledge acquisition capacity still reflects the user's willingness to innovate to a certain extent. Users with stronger knowledge acquisition capabilities have higher efficiency in identifying and acquiring external knowledge and stronger creative willingness. They are more likely to produce contribution behaviors. And the promotion of user's network position will be more obvious. Therefore, the following hypotheses are proposed:

$\mathrm{H}_{4 \mathrm{a}}$ : the user's knowledge acquisition capacity plays a mediator role between the degree centrality and proactive contribution behavior

$\mathrm{H}_{4 \mathrm{~b}}$ : the user's knowledge acquisition capacity plays a mediator role between the eigenvector centrality and proactive contribution behavior

$\mathrm{H}_{4 \mathrm{c}}$ : the user's knowledge acquisition capacity plays a mediator role between the structural hole and proactive contribution behavior

$\mathrm{H}_{4 \mathrm{~d}}$ : the user's knowledge acquisition capacity plays a mediator role between the degree centrality and responsive contribution behavior

$\mathrm{H}_{4 \mathrm{e}}$ : the user's knowledge acquisition capacity plays a mediator role between the eigenvector centrality and responsive contribution behavior

$\mathrm{H}_{4 \mathrm{f}}$ : the user's knowledge acquisition capacity plays a mediator role between the structural hole and responsive contribution behavior

\subsubsection{The Mediating Effect of Knowledge Application} Capacity. Any incremental knowledge can only reflect its value through practical application, and this process needs the support of the user's knowledge application capacity. Therefore, the user's knowledge application capacity can expand the advantages of their network positions and transform them into contribution behaviors. The stronger the user's knowledge application capacity, the more obvious the promotion effect of their network attribute on their contribution behavior. Therefore, the following hypotheses are proposed: 
$\mathrm{H}_{4 \mathrm{~g}}$ : the user's knowledge application capacity plays a mediator role between the degree centrality and proactive contribution behavior

$\mathrm{H}_{4 \mathrm{~h}}$ : the user's knowledge application capacity plays a mediator role between the eigenvector centrality and proactive contribution behavior.

$\mathrm{H}_{4 \mathrm{i}}$ : the user's knowledge application capacity plays a mediator role between the structural hole and proactive contribution behavior

Based on the above analysis, the conceptual model of the impacts of users' network positions and knowledge absorption capacity on their crowdsourcing innovation contribution behavior is shown in Figure 1. The related assumptions are hypotheses in Table 1.

\section{Research Methodology}

4.1. Data Source. The "Developer Communication" section of the MIUI community is the main section for the communication between community users, the development team, and developers. MIUI officials will regularly appraise the quality of posts and mark posts with practical significance. Using the web crawler collector (Octopus version 7.5.4), the relevant data of the participating users of the "Essence Posts" are obtained from January 2014 to September 2019.

\subsection{Measurements}

4.2.1. Dependent Variables. Existing research generally takes the number of innovative ideas to measure the user's contribution behavior simply. For the crowdsourcing innovation community, users' contribution behavior is not only the direct contribution behavior for innovation.

Although users post comments and provide suggestions on other users' topics and they cannot directly achieve innovation, this behavior outputs knowledge to knowledge seekers and indirectly promotes innovation.

Therefore, this paper will measure the user's contribution behavior from two dimensions: the user's active contribution behavior and reactive contribution behavior. Among them, the number of users actively publishing topic posts is used to measure the user's active contribution behavior, and the number of users submitting comments is used to measure the user's response contribution behavior.

\subsubsection{Independent Variables}

(1) Degree centrality refers to the number of other nodes directly connected to the node. And it mainly measures the size of the user's individual network in the knowledge interaction network. Therefore, this article uses the number of other users who have direct contact with the user to measure the network scale.

(2) Eigenvector centrality measures the importance of nodes in the network. The user's eigenvector centrality depends not only on the number of directly connected other users but also on the importance of these users. The calculation formula of eigenvector centrality refers to the research of Bonacich [25]:

$$
\begin{aligned}
\mathrm{EC}(i) & =x_{i} \\
& =c \sum_{j=1}^{n} a_{i j} x_{j},
\end{aligned}
$$

where $c$ is the proportional factor, $x_{i}$ is the importance value of node $i$, and $a_{i j}$ is the connection coefficient (if node $i$ is connected to node $j$, the value of $a_{i j}$ is 1 , otherwise it is 0 ).

(3) Although Burt proposes four measurements (Effective size, Efficiency, Constraint, and Hierarchy), scholars generally prefer Constraint to measure the user's structural hole [20,38]. Constraint measures the direct or indirect closeness of a node in the network to other nodes, characterizing the closure of individual networks. The value of Constraint is in inverse proportion to the number of structural holes, and the user's Constraint can be calculated by the following equation:

$$
C_{i j}=\left(p_{i j}+\sum p_{i j} p_{k j}\right)^{2}, \quad k \neq i, j,
$$

where $p_{i j}$ is the ratio of the contacts of user $i$ to user $k$ to the contacts of the user $i$ to other users. According to the above hypothesis, it can be seen that the structural hole has a positive influence on user's contribution behavior, and it can be inferred that the Constraint is negatively related to user's contribution. Therefore, this paper uses the difference between 1 and the Constraint as an indicator to measure the user's ability to use structural holes.

However, the use of Constraint as an indicator to measure structural holes can only reflect how many structural holes users occupy, ignoring the concentration of structural holes. This article introduces Constraint to reflect the extent to which restrictions are concentrated on one user. The calculation formula is as follows:

$$
H=\frac{\sum_{j} C / C / N \operatorname{In} C_{i j} / C / N}{N \operatorname{In}(N)},
$$

where $N$ is the network scale of user $i, C / N$ is the average value of the Constraint of each user, and $N \operatorname{In}(N)$ represents the maximum possible sum value. As with the Constraint, this article speculates that Hierarchy is negatively related to user's contributions. Therefore, this paper uses the difference between 1 and Hierarchy as an indicator to measure the concentration of user structure holes. At the same time, this article uses principal component analysis to extract a common factor from the two indicators of Constraint and Hierarchy to measure the structural holes of users. The results show that the total variation explained by extracting common factors reaches $92.85 \%$, which has a high degree of explanation. 


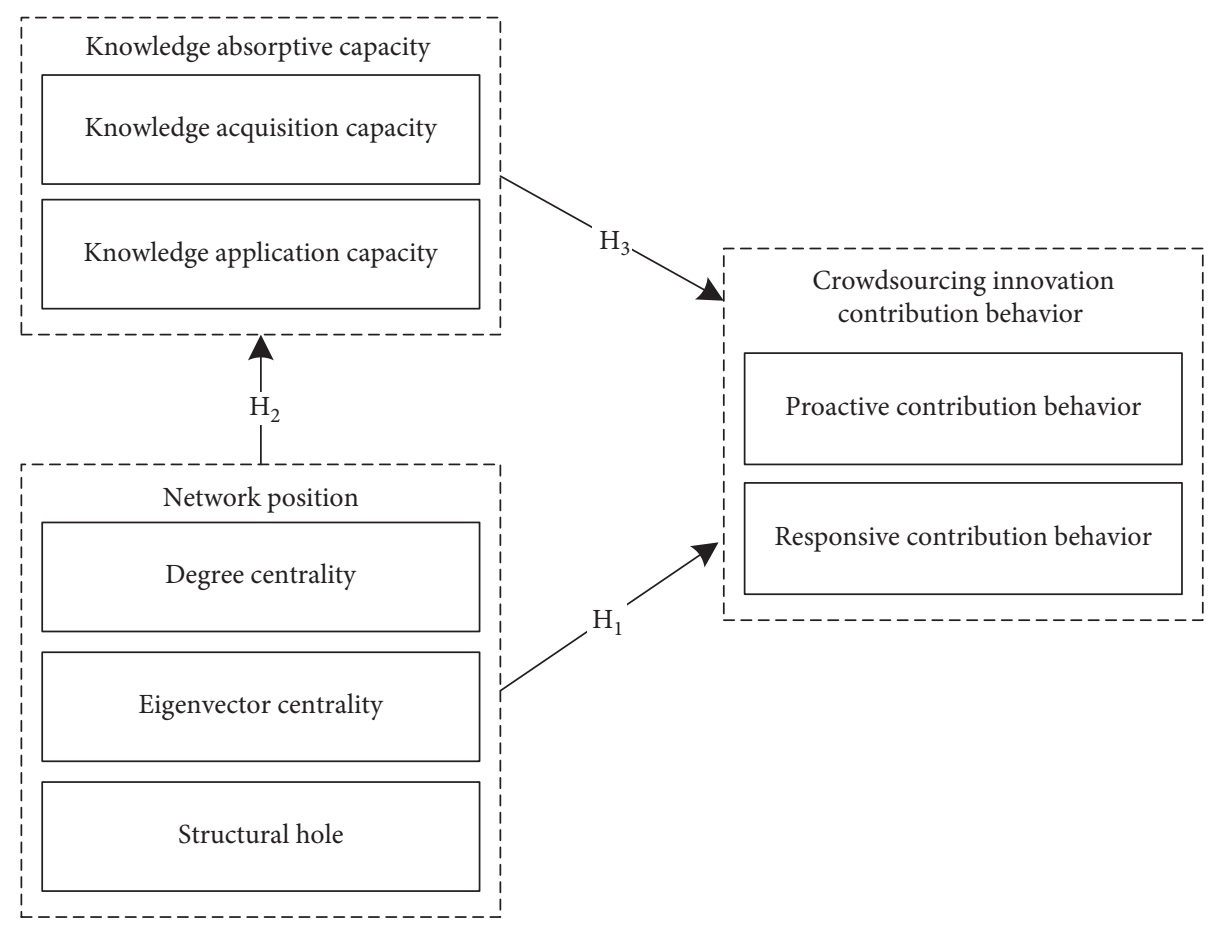

Figure 1: Research model.

TABLE 1: The summary table of hypotheses.

\begin{tabular}{|c|c|}
\hline No. & The description of hypotheses \\
\hline $\mathrm{H}_{1 \mathrm{a}}$ & The user's degree centrality has a positive impact on his/her proactive contribution behavior \\
\hline $\mathrm{H}_{1 \mathrm{~b}}$ & The user's degree centrality has a positive impact on his/her responsive contribution behavior \\
\hline $\mathrm{H}_{1 \mathrm{c}}$ & The user's eigenvector centrality has a positive impact on his/her proactive contribution behavior \\
\hline $\mathrm{H}_{1 \mathrm{~d}}$ & The user's eigenvector centrality has a positive impact on his/her responsive contribution behavior \\
\hline $\mathrm{H}_{1 \mathrm{e}}$ & The user's structural hole has a positive impact on his/her proactive contribution behavior \\
\hline $\mathrm{H}_{1 \mathrm{f}}$ & The user's structural hole has a positive impact on his/her responsive contribution behavior \\
\hline $\mathrm{H}_{2 \mathrm{a}}$ & The user's knowledge acquisition capacity has a positive impact on his/her proactive contribution \\
\hline $\mathrm{H}_{2 \mathrm{~b}}$ & The user's knowledge acquisition capacity has a positive influence on his/her responsive contribution \\
\hline $\mathrm{H}_{2 \mathrm{c}}$ & The user's knowledge application capacity has a positive impact on his/her proactive contribution \\
\hline $\mathrm{H}_{3 \mathrm{a}}$ & The user's degree centrality has a positive impact on his/her knowledge acquisition capacity \\
\hline $\mathrm{H}_{3 \mathrm{~b}}$ & The user's eigenvector centrality has a positive impact on his/her knowledge acquisition capacity \\
\hline $\mathrm{H}_{3 \mathrm{c}}$ & The user's structural hole has a positive impact on his/her knowledge acquisition capacity \\
\hline $\mathrm{H}_{3 \mathrm{~d}}$ & The user's degree centrality has a positive impact on his/her knowledge application capacity \\
\hline & The user's structural hole has a positive impact on his/her knowledge application capacity \\
\hline & The user's knowledge acquisition capacity plays a mediator role between the degree centrality and proactive contribution behavior \\
\hline & $\begin{array}{c}\text { The user's knowledge acquisition capacity plays a mediator role between the eigenvector centrality and proactive contribution } \\
\text { behavior }\end{array}$ \\
\hline & $\begin{array}{l}\text { The user's knowledge acquisition capacity plays a mediator role between the structural hole and proactive contribution behavior } \\
\text { The user's knowledge acquisition capacity plays a mediator role between the degree centrality and responsive contribution behavior }\end{array}$ \\
\hline & $\begin{array}{c}\text { The user's knowledge acquisition capacity plays a mediator role between the eigenvector centrality and responsive contribution } \\
\text { behavior }\end{array}$ \\
\hline & $\begin{array}{l}\text { The user's knowledge acquisition capacity plays a mediator role between the structural hole and responsive contribution behavior } \\
\text { The user's knowledge application capacity plays a mediator role between the degree centrality and proactive contribution behavior }\end{array}$ \\
\hline & $\begin{array}{c}\text { The user's knowledge application capacity plays a mediator role between the eigenvector centrality and proactive contribution } \\
\text { behavior }\end{array}$ \\
\hline $\mathrm{H}_{4 \mathrm{i}}$ & The user's knowledge application capacity plays a mediator role between the structural hole and proactive contribution behav \\
\hline
\end{tabular}

4.2.3. Mediator Variable. The user's knowledge acquisition capacity determines the efficiency of the user's identification and acquisition of effective knowledge from external knowledge streams [2]. Although it does not directly achieve innovation, one of the crowdsourcing innovation community's functions is to improve the overall knowledge 
structure of users to achieve innovation through the process of "acquisition-re-dissemination." Users acquire/share knowledge through interactive communication and establish stable relationships between users through frequent interactions to achieve continuous knowledge input. Therefore, this article chooses the stable information source established by the user (i.e., the number of interactions is greater than or equal to 3 times) as an index to measure the user's knowledge acquisition capacity.

The user's knowledge application capacity directly affects the quantity and quality of user innovation [2]. Some scholars use the number of officially recognized innovations as an index to measure the user's knowledge application capacity. But it has some shortcomings in measuring the user's knowledge application capacity. On the one hand, the officially recognized innovations have higher requirements for users' knowledge application capacity, ignoring some improved knowledge applications; on the other hand, for most users, due to limitation of educational background and skills, their knowledge application is still in the initial stage of "integration \& sharing." Therefore, this article does not use the number of officially recognized innovations as a measure. For the crowdsourcing innovation community, elementary knowledge integration \& sharing and highquality knowledge application innovation are indispensable. This article ignores whether the content is officially recognized or highly innovative and chooses the number of topics published by users as the indicator as shown in Table 2 .

\section{Hypothesis Testing}

5.1. Descriptive Statistics. Table 3 shows the descriptive statistical analysis of each research variable, and Table 4 shows the correlation coefficient and VIF (variance inflation factor, VIF) value of each research variable. It can be seen that the VIF of each variable is below 10, so there is no multicollinearity problem among the research variables [41].

5.2. Regression Model Selection. This article involves four dependent variables: knowledge acquisition capacity, knowledge application capacity, proactive contribution behavior, and responsive contribution behavior. And the four variables are all nonnegative integers. It can be seen from Table 3 that the variances of the four variables are quite different from averages, indicating that the variables are "over-dispersed." Therefore, this paper selects the negative binomial regression model suitable for processing discrete data and uses Stata15 for regression analysis.

\subsection{Results of Regression Analysis}

5.3.1. User's Network Position and Crowdsourcing Innovation Contribution Behavior. The regression results of hypothesis 1 are shown in Table 5. The dependent variables of model 1 to model 3 are proactive contribution behavior, and the dependent variables of model 4 to model 6 are p-responsive contribution behavior.
In Model 1 and Model 4, there is a significant positive correlation between the user's degree centrality and their crowdsourced innovation contribution behavior (the coefficient of proactive contribution behavior $\beta=0.140, p<0.01$; the coefficient of responsive contribution behavior $\beta=0.009$, $p<0.01)$. The result proves that the user with a higher degree centrality will be more likely to make proactive contribution behavior, providing support to $\mathrm{H}_{1 \mathrm{a}}$ and $\mathrm{H}_{1 \mathrm{~b}}$.

Model 2 proves the user's eigenvector centrality positively affects their proactive contribution behavior $(\beta=0.226)$. But eigenvector centrality has no significant impact $(p<0.01) . \mathrm{H}_{1 \mathrm{c}}$ is not supported. In model 5 , there is a significant positive impact between the user's eigenvector centrality and responsive contribution behavior $(\beta=0.226$, $p<0.01$ ), and $\mathrm{H}_{1 \mathrm{~d}}$ is supported. Research by Liu et al. shows that the subject with a high eigenvector centrality has high knowledge transfer effectiveness. The sample data analysis shows that 7023 users have submitted 120 ideas/suggestions, but there are 10511 comments. It can determine that knowledge transfer among users of the crowdsourcing innovation virtual community is mainly in comments. Simultaneously, the user attribute analysis shows that users with high eigenvector centrality are often keen to comment on topics published by core users rather than posting topics. Therefore, eigenvector centrality significantly promotes responsive contribution behavior rather than proactive contribution behavior.

In Model 3 and Model 6, the structural holes positively and significantly affect crowdsourced innovation contribution behavior. Contrary to the conclusion of scholars such as Liu et al. [42] and Xiao and Tsui [43], there are apparent structural hole advantages in the crowdsourcing innovation knowledge interaction network. $\mathrm{H}_{1 \mathrm{e}}$ and $\mathrm{H}_{1 \mathrm{f}}$ are supported.

\subsubsection{User's Knowledge Absorption Capacity and Crowd-} sourcing Innovation Contribution Behavior. Table 6 shows the regression results of hypothesis 2 , the dependent variables of Model 7 and Model 8 are proactive contribution behavior, and the dependent variable of Model 9 is responsive contribution behavior.

Model 7 and Model 9 show knowledge acquisition capacity significantly affects crowdsourcing innovation contribution (the regression coefficient with proactive contribution behavior is $\beta=1.675, p<0.01$; the regression coefficient with responsive contribution behavior is $\beta=0.338, p<0.01$ ), providing support to $\mathrm{H} 2 \mathrm{a}$ and $\mathrm{H}_{2 \mathrm{~b}}$. Model 5 holds the user's knowledge application capacity has a significant positive impact on proactive contribution behavior $(\beta=0.004, p<0.1) . \mathrm{H}_{2 \mathrm{c}}$ is supported.

5.3.3. User's Network Position and Their Knowledge Absorption Capacity. Table 7 shows the regression results of hypothesis 3, the dependent variables of Model 10 to Model 12 are knowledge acquisition capacity, and the dependent variable of Model 13 and Model 14 is knowledge application capacity.

The regression result of Model 10 shows that the user's degree centrality positively affects the knowledge acquisition 
TABLE 2: The measurement of each research variable.

\begin{tabular}{|c|c|c|c|}
\hline Variable type & Variable name & The measurement of the variable & References \\
\hline $\begin{array}{l}\text { Dependent } \\
\text { variables }\end{array}$ & $\begin{array}{l}\text { Knowledge } \\
\text { acquisition capacity } \\
\text { Knowledge } \\
\text { application capacity }\end{array}$ & $\begin{array}{l}\text { The number of posts that users actively publish and are } \\
\text { officially recognized or widely followed by other users in } \\
\text { a specific period } \\
\text { The number of users' answers, comments, and opinions } \\
\text { on other users' opinions }\end{array}$ & $\begin{array}{c}\text { Atuahene-Gima et al [39]; Nambisan } \\
\text { and baron [16]; Mahr and Lievens [17]; } \\
\text { Qin et al. [18] }\end{array}$ \\
\hline $\begin{array}{l}\text { Independent } \\
\text { variables }\end{array}$ & $\begin{array}{l}\text { Degree centrality } \\
\text { Eigenvector } \\
\text { centrality } \\
\text { Structural hole }\end{array}$ & $\begin{array}{l}\text { The number of other users who have direct contact with } \\
\text { the user } \\
\text { The comprehensive value of the user's centrality in } \\
\text { contact with the user } \\
\text { The common factors of constraint and hierarchy }\end{array}$ & $\begin{array}{c}\text { Bonacich [25] } \\
\text { Burt [40] }\end{array}$ \\
\hline $\begin{array}{l}\text { Mediator } \\
\text { variable }\end{array}$ & $\begin{array}{c}\text { Proactive } \\
\text { contribution } \\
\text { behavior } \\
\text { Responsive } \\
\text { contribution } \\
\text { behavior }\end{array}$ & $\begin{array}{l}\text { The number of stable information sources established } \\
\text { through frequent interaction } \\
\text { The number of posts by users, including knowledge- } \\
\text { sharing posts and innovative application posts }\end{array}$ & Tsai [11]; Qian et al. [3]; Qin et al. [18] \\
\hline
\end{tabular}

TABle 3: Descriptive statistical analysis.

\begin{tabular}{|c|c|c|c|c|c|c|c|}
\hline Variable & Number of cases & Minimum & Maximum & Average & Variance & Skewness & Kurtosis \\
\hline Degree centrality & 7023 & 1 & 703 & 2.50 & 289.750 & 27.861 & 953.958 \\
\hline Eigenvector centrality & 7023 & 0.000 & 140.147 & 0.04634 & 2.846 & 81.629 & 6776.477 \\
\hline Structural hole & 7023 & -0.31575 & 5.75476 & -0.0008414 & 0.998 & 3.062 & 8.175 \\
\hline Knowledge acquisition capacity & 7023 & 0 & 15 & 0.02 & 0.125 & 29.026 & 997.936 \\
\hline Knowledge application capacity & 7023 & 0 & 1221 & 18.92 & 2008.658 & 9.809 & 165.978 \\
\hline Proactive contribution behavior & 7023 & 0 & 4 & 0.02 & 0.039 & 11.130 & 147.569 \\
\hline Responsive contribution behavior & 7023 & 0 & 211 & 1.50 & 8.214 & 57.785 & 4102.124 \\
\hline
\end{tabular}

TABle 4: The correlation coefficient and VIF value.

\begin{tabular}{|c|c|c|c|c|c|c|c|c|}
\hline Variable & $\begin{array}{c}\text { Degree } \\
\text { centrality }\end{array}$ & $\begin{array}{c}\text { Eigenvector } \\
\text { centrality }\end{array}$ & $\begin{array}{l}\text { Structural } \\
\text { hole }\end{array}$ & $\begin{array}{c}\text { Knowledge } \\
\text { acquisition } \\
\text { capacity }\end{array}$ & $\begin{array}{c}\text { Knowledge } \\
\text { application } \\
\text { capacity }\end{array}$ & $\begin{array}{c}\text { Proactive } \\
\text { contribution } \\
\text { behavior }\end{array}$ & $\begin{array}{c}\text { Responsive } \\
\text { contribution } \\
\text { behavior }\end{array}$ & VIF \\
\hline Degree centrality & 1.000 & & & & & & & 1.81 \\
\hline $\begin{array}{l}\text { Eigenvector } \\
\text { centrality }\end{array}$ & $0.169^{* * *}$ & 1.000 & & & & & & 4.79 \\
\hline Structural hole & $0.124^{* * *}$ & 0.0180 & 1.000 & & & & & 1.16 \\
\hline $\begin{array}{l}\text { Knowledge } \\
\text { acquisition } \\
\text { capacity }\end{array}$ & $0.635^{* * *}$ & $0.130^{* * *}$ & $0.068^{* * *}$ & 1.000 & & & & 1.72 \\
\hline $\begin{array}{l}\text { Knowledge } \\
\text { application } \\
\text { capacity }\end{array}$ & $0.022 *$ & -0.003 & $0.066^{* * *}$ & $0.032^{* * *}$ & 1.000 & & & 5.47 \\
\hline $\begin{array}{l}\text { Proactive } \\
\text { contribution } \\
\text { behavior }\end{array}$ & $0.581^{* * *}$ & $0.192^{* * *}$ & $0.179^{* * *}$ & $0.569^{* * *}$ & $0.047^{* * *}$ & 1.000 & & - \\
\hline $\begin{array}{l}\text { Responsive } \\
\text { contribution } \\
\text { behavior }\end{array}$ & $0.312^{* * *}$ & $0.873^{* * *}$ & $0.191^{* * *}$ & $0.253^{* * *}$ & $0.039^{* * *}$ & $0.336^{* * *}$ & 1.000 & - \\
\hline
\end{tabular}

capacity. But the degree centrality has no significant effect. $\mathrm{H}_{3 \mathrm{a}}$ is not supported. Model 13 shows that the user's degree centrality significantly promotes their knowledge application capacity $(\beta=0.002, p<0.05)$, supporting $\mathrm{H}_{3 \mathrm{~b}}$.
Model 11 shows that the user's eigenvector centrality is significantly positively correlated with knowledge acquisition capacity $(\beta=0.037, p<0.001)$, indicating that the higher the user's eigenvector centrality, the higher the 
TABLE 5: The regression results of hypothesis 1.

\begin{tabular}{|c|c|c|c|c|c|c|}
\hline \multirow{2}{*}{ Variables } & \multicolumn{3}{|c|}{ Proactive contribution behavior } & \multicolumn{3}{|c|}{ Responsive contribution behavior } \\
\hline & Model 1 & Model 2 & Model 3 & Model 4 & Model 5 & Model 6 \\
\hline Degree centrality & $0.140^{* * *}(0.000)$ & & & $\begin{array}{c}0.009^{* * *} \\
(0.000)\end{array}$ & & \\
\hline Eigenvector centrality & & $0.226(0.246)$ & & & $0.032^{* * *}(0.000)$ & \\
\hline Structural hole & & & $1.446^{* * *}(0.000)$ & & & $0.230^{* * *}(0.000)$ \\
\hline
\end{tabular}

Note. ${ }^{* *} p<0.05 ;{ }^{*} p<0.1$.

TABLE 6: The regression results of hypothesis 2 .

\begin{tabular}{|c|c|c|c|}
\hline \multirow{2}{*}{ Variables } & \multicolumn{2}{|c|}{ Proactive contribution behavior } & \multirow{2}{*}{$\begin{array}{l}\text { Responsive contribution behavior } \\
\text { Model } 9\end{array}$} \\
\hline & Model 7 & Model 8 & \\
\hline Knowledge acquisition capacity & $1.675^{* * *}(0.000)$ & & $0.338^{* * *}(0.000)$ \\
\hline Knowledge application capacity & & $0.004^{*}(0.059)$ & \\
\hline
\end{tabular}

Note. ${ }^{* * *} p<0.01 ;{ }^{* *} p<0.05 ;{ }^{*} p<0.1$.

TABLE 7: The regression results of hypothesis 3 .

\begin{tabular}{|c|c|c|c|c|c|}
\hline \multirow{2}{*}{ Variables } & \multicolumn{3}{|c|}{ Knowledge acquisition capacity } & \multicolumn{2}{|c|}{ Knowledge application capacity } \\
\hline & Model 10 & Model 11 & Model 12 & Model 13 & Model 14 \\
\hline Degree centrality & $0.093(0.170)$ & & & $0.002^{* *}(0.013)$ & \\
\hline Eigenvector centrality & & $0.037^{* * *}(0.000)$ & & & \\
\hline Structural hole & & & $0.561^{* * *}(0.000)$ & & $0.109^{* * *}(0.000)$ \\
\hline
\end{tabular}

quality of contact, and the stronger their knowledge acquisition capacity. $\mathrm{H}_{3 \mathrm{c}}$ is supported.

Model 12 and Model 14 show that the structural hole significantly impacts the user's knowledge absorptive capacity (the regression coefficient with knowledge acquisition capacity is $\beta=0.561, p<0.01$; the regression coefficient with knowledge application capacity is $\beta=0.109, p<0.01)$. H3d and $\mathrm{H} 3 \mathrm{e}$ are verified.

5.3.4. The Mediating Effect of User's Knowledge Absorptive Capacity between Network Position and Crowdsourcing Innovation Contribution Behavior. The regression results of hypothesis 4 are shown in Table 8 . The dependent variables of Model 15 to Model 18 are proactive contribution behavior, and the dependent variables of Model 19 to Model 23 are responsive contribution behavior. Since $\mathrm{H}_{1 \mathrm{c}}$ is not supported, eigenvector centrality does not significantly affect the user's proactive contribution behavior. So it is determined that $\mathrm{H}_{4 \mathrm{c}}$ (Model 20) and $\mathrm{H}_{4 \mathrm{~d}}$ (Model 22) are not valid [44].

In Model 15, the degree centrality's coefficient and knowledge acquisition capacity's coefficient are both significant. But since the influence of degree centrality on knowledge acquisition capacity in Model 10 is not substantial, the Sobel test is needed to determine whether knowledge acquisition capacity has a mediating effect $[44,45]$. It is found that the regression coefficient of knowledge acquisition capacity is $\beta=0.187(p<0.01)$, so knowledge acquisition capacity has a partial mediating effect between degree centrality and proactive contribution behavior, providing some partial support to $\mathrm{H}_{4 \mathrm{a}}$.

Model 8 and Model 13 verify that the user's degree centrality significantly impacts their knowledge application capacity, and the change of knowledge application capacity significantly affects proactive contribution behavior. Model 1 shows that the degree centrality substantially affects the user's proactive contribution behavior. Simultaneously in Model 16, the degree centrality's coefficient and the knowledge application capacity's coefficient are both significant, so the knowledge application capacity plays a partially mediating role between the degree centrality and proactive contribution behavior, partially supporting the $\mathrm{H}_{4 \mathrm{~b}}$. Similarly, $\mathrm{H}_{4 \mathrm{e}}, \mathrm{H}_{4 \mathrm{~g}}$, $\mathrm{H}_{4 \mathrm{~h}}$, and $\mathrm{H}_{4 \mathrm{i}}$ are all partially supported.

Model 9 and Model 14 verify that the user's structural hole has a significant impact on knowledge application capacity, while changes in knowledge application capacity significantly affect the user's proactive contribution behavior. Model 3 verifies that the structural hole can promote proactive contribution behavior. But the coefficient of knowledge application capacity in Model 18 is not significant. And the Sobel test result shows that the regression coefficient of knowledge application capacity is $-0.0001(p<0.1) . \mathrm{H}_{4 \mathrm{f}}$ is rejected.

\section{Findings and Discussion}

6.1. Theoretical Finding. Based on the above empirical research on the impacts of the user's network position and knowledge absorption capacity on their crowdsourcing 
TABLE 8: The regression results of hypothesis 4 .

\begin{tabular}{|c|c|c|c|c|c|c|c|}
\hline \multirow{2}{*}{ Variables } & \multicolumn{4}{|c|}{ Proactive contribution behavior } & \multicolumn{3}{|c|}{ Responsive contribution behavior } \\
\hline & Model 15 & Model 16 & Model 17 & Model 18 & Model 19 & Model 21 & Model 23 \\
\hline Degree centrality & $\begin{array}{c}0.013^{* * *} \\
(0.000)\end{array}$ & $\begin{array}{c}0.011^{* *} \\
(0.001)\end{array}$ & & & $\begin{array}{c}0.008^{* * *} \\
(0.000)\end{array}$ & & \\
\hline Eigenvector centrality & & & & & & $\begin{array}{c}0.039^{* * *} \\
(0.000)\end{array}$ & \\
\hline Structural hole & & & $\begin{array}{c}0.661^{* * *} \\
(0.000)\end{array}$ & $\begin{array}{c}0.633^{* * *} \\
(0.000)\end{array}$ & & & $\begin{array}{c}0.230^{* * *} \\
(0.000)\end{array}$ \\
\hline $\begin{array}{l}\text { Knowledge acquisition } \\
\text { capacity }\end{array}$ & $\begin{array}{c}0.129^{* * *} \\
(0.012)\end{array}$ & & $\begin{array}{c}0.188^{* * *} \\
(0.001)\end{array}$ & & $\begin{array}{c}0.120^{* * *} \\
(0.000)\end{array}$ & $\begin{array}{c}0.1001^{* * *} \\
(0.000)\end{array}$ & $\begin{array}{c}0.263^{* * *} \\
(0.000)\end{array}$ \\
\hline $\begin{array}{l}\text { Knowledge application } \\
\text { capacity }\end{array}$ & & $\begin{array}{c}0.002^{* * *} \\
(0.052)\end{array}$ & & $0.001(0.628)$ & & & \\
\hline
\end{tabular}

Note. ${ }^{* * *} p<0.01 ;{ }^{* *} p<0.05 ;{ }^{*} p<0.1$.

innovation contribution behavior, the following conclusions are obtained:

(1) In general, the user's network position has a positive impact on their crowdsourcing innovation contribution behavior to varying degrees. But not all variables of network position have a significant positive effect on their crowdsourcing innovation contribution behavior. Users located in the center of the network with a large number of direct contacts and occupied a wealth of structural holes have a significant advantage in knowledge acquisition. Von Hippel [46] believes that the purchase and exchange of knowledge rely on the connection between subjects. The purchase of new knowledge plays a vital role in innovation, so subjects need to occupy a favorable position. This study shows that the user's degree centrality and structural holes have a significant promotion effect on both proactive contribution behavior and responsive contribution behavior. The eigenvector centrality significantly stimulates the generation of user's responsive contribution behavior.

(2) Both knowledge acquisition capacity and knowledge application capacity promote the crowdsourcing innovation behavior of users. While trying to occupy a favorable network position and increase knowledge exchange with other users, users should also continuously improve their knowledge absorption capacity to enhance their crowdsourcing innovation performance. This study believes that both users' proactive and responsive contributions contribute to the improvement of innovation performance. As a crowdsourcing platform, crowdsourcing platform establishment's ultimate goal is to obtain users' innovative ideas. Therefore, for users, it is necessary to pay attention to improve personal knowledge absorption ability and increase investment in cultivating their own abilities; for crowdsourcing platforms, it is necessary to formulate strategies to encourage enterprise personnel, core users, and other innovative entities to conduct knowledge exchanges with community users and create a good knowledge-sharing atmosphere, thereby enhancing the overall knowledge absorption capacity of community users, so as to improve the overall crowdsourcing innovation contribution behavior of the community.

(3) The research results show that the user's knowledge acquisition capacity has a partial mediating effect between the network position and crowdsourcing innovation contribution behavior. There is only a partial mediating effect between the user's degree centrality and proactive contribution behavior, and there is no mediating effect between the user's structural hole and proactive contribution behavior. The analysis of relevant data shows that users who occupy a large number of structural holes identify themselves as "knowledge porters" and mainly act as intermediaries in the network. This kind of user mostly makes crowdsourcing innovation and proactive contribution behaviors by publishing heterogeneous knowledge topic posts obtained through integration. It does not require users with a high knowledge application capacity. Therefore, the knowledge application capacity is no mediating effect between the structural hole and proactive contribution behavior. In general, users' knowledge absorbing capacity has a significant mediating effect on network position and crowdsourcing innovation contribution behavior.

6.2. Practical Enlightenment. In addition to the theoretical findings, the paper provides the following implications for managers:

(1) Create a friendly and harmonious user interaction environment, build a good and orderly knowledgesharing platform, and improve users' willingness to share knowledge. Thanks to the full participation of the public, the MIUI community has gathered a large number of active users within a short period of time after its establishment. However, the quality of users is uneven and conflicts occur from time to time in the community, causing a large number of users with high-quality innovation potential to disappoint and withdraw from the community. Therefore, the community platform first needs to arrange a 
dedicated person to manage the order of the community, resolutely eliminate the "problem stickers," and clear out the "trouble users," so as to create a friendly and harmonious user interaction environment. Secondly, the knowledge required for innovation is often scattered among users of different backgrounds in the community. How to accelerate the flow and aggregation of knowledge so as to achieve innovation is the strategic goal of platform management. Research shows that users who are located at the center of the network have a large number of direct contacts and occupy a wealth of structural holes that have significant advantages in knowledge acquisition and digestion. Therefore, on the one hand, the community needs to promote users' willingness to participate in knowledge interaction actively, establish a knowledge-sharing network with other core users, and occupy a favorable position on the network to improve their crowdsourcing innovation performance; on the other hand, the community also should encourage users to communicate cross-border to establish knowledge exchange relationships with users with different knowledge backgrounds, and strive to act as an intermediary between groups of varying knowledge and skill backgrounds, widely absorb heterogeneous knowledge, and form their knowledge and skills advantages.

(2) Increase investment in user training and improve user knowledge absorptive capacity. The user's knowledge absorptive capacity, whether it is the knowledge acquisition capacity or the knowledge application capacity, promotes the user's innovative contribution behavior. Although both proactive and responsive contributions of users can contribute to the improvement of innovation performance, as a crowdsourcing innovation community, the ultimate purpose of community establishment is to obtain users' innovative ideas. Therefore, community managers need to formulate strategies to improve user's knowledge absorptive capacity, encourage enterprise personnel, core users, and other innovative entities to exchange knowledge with community users, and create a good knowledge-sharing atmosphere, so as to enhance the overall knowledge absorptive capacity of community users and improve the possibility of innovation contribution behavior occurring.

(3) Pay attention to "knowledge porters," increase the degree of connectivity of the community's knowledgesharing network, and reduce the possibility of missing knowledge transmission. Users who often occupy a large number of structural holes in the community consider themselves as "knowledge porters" and mainly act as intermediaries in the network. Such users mainly make innovative and active contributions by publishing posts of integrating heterogeneous knowledge. Although this action does not directly make substantial innovations, it has continuously increased the circulation of community information and the attention of topics to promote more potential sources of innovation to make real innovation [47]. Therefore, the community needs to increase its attention to such users, increase their rewards to ensure the activity of the community, and increase the circulation of knowledge.

\section{Limitation and Future Directions}

Analyzing the influence relationship between users' network position and their crowdsourcing innovation contribution behavior is of great significance for guiding and motivating the public to actively and continuously participate in crowdsourcing innovation and improving the performance of crowdsourcing innovation. This paper combines social network theory and the individual mindset to introduce knowledge absorptive capacity into the relationship model of the user's network position and crowdsourcing innovation contribution behavior, thereby constructing a complete path of "knowledge supply-knowledge acquisition-knowledge application-knowledge output." And trying to open the "relationship black box" between the user's network position and their crowdsourced innovation contribution behavior, the empirical test is carried out with the relevant data of the MIUI community. The study provides that the user at the center of the network is more likely to contribute. The user's knowledge absorption capacity helps to stimulate the crowdsourcing innovation contribution behavior. The stronger the user's knowledge absorption capacity, the higher the possibility of users transforming the network position advantages into an innovative contribution behavior. The research provides a theoretical basis for an in-depth understanding of the influence relationship between the user's network position and their crowdsourcing innovation contribution behavior. Also, it provides a reference for enterprises to carry out practical crowdsourcing innovation community governance and improve innovation performance.

The study also has the following shortcomings: the relevant data only come from the "Developer Communication" section of the MIUI community, which mainly considers that this section has strong crowdsourcing innovation characteristics. And experimental data do not cover other crowdsourcing innovation virtual communities. To a certain extent, it affects the universality of research conclusions. In addition, the data used in this article are cross-sectional data, and more strict causality exploration needs to collect longitudinal data to test.

\section{Data Availability}

The "Developer Communication" section (http://xiaomi.cn/ board/558495) of the MIUI community is the main section for the communication between community users, the 
development team, and developers. Using the web crawler collector (Octopus version 7.5.4), the relevant data of the participating users of the "Essence Posts" are obtained from January 2014 to September 2019.

\section{Conflicts of Interest}

The authors declare that they have no conflicts of interest.

\section{Acknowledgments}

This work was supported by Subsequent Funding Projects of NSSFC 19FGLB019, Social Science Fund of MOE under Grant 19YJA630055, and Jiangsu Social Science Fund under Grant 20GLB016.

\section{References}

[1] J. Howe, "The rise of crowdsourcing," Wired Magazine, vol. 14, no. 6, pp. 1-4, 2006.

[2] B. L. Bayus, "Crowdsourcing new product ideas over time: an analysis of the Dell IdeaStorm community," Management Science, vol. 59, no. 1, pp. 226-244, 2013.

[3] X. H. Qian, Y. F. Yang, and W. L. Xu, "The position of firms' Network,the absorptive Capacity,and the performance in innovation," Management World, vol. 5, pp. 118-129, 2010.

[4] C. Beaudry and S. Breschi, "Are firms in clusters really more innovative," Economics of Innovation and New Technology, vol. 12, no. 4, pp. 325-342, 2003.

[5] J. H. Dyer and K. Nobeoka, "Creating and managing a highperformance knowledge-sharing network: the Toyota case," Strategic Management Journal, vol. 21, no. 3, pp. 345-367, 2000.

[6] A. G. Karamanos, "Effects of a firm's and their partners' alliance ego-network structure on its innovation output in an era of ferment," $R$ \& $D$ Management, vol. 46, no. S1, pp. 261-276, 2016.

[7] G. G. Bell, "Clusters, networks, and firm innovativeness," Strategic Management Journal, vol. 26, no. 3, pp. 287-295, 2005.

[8] S. A. Zahra and G. George, "Absorptive capacity: a review, reconceptualization, and extension," Academy of Management Review, vol. 27, no. 2, pp. 185-203, 2002.

[9] R. Sternberg and O. Arndt, "The firm or the region: what determines the innovation behavior of European firms?" Economic Geography, vol. 77, no. 4, pp. 364-382, 2001.

[10] M. A. Hitt, R. D. Ireland, D. G. Sirmon, and C. A. Trahms, "Strategic entrepreneurship: creating value for individuals, organizations, and society," Academy of Management Perspectives, vol. 25, no. 2, pp. 57-75, 2011.

[11] W. Tsai, "Knowledge transfer in intraorganizational networks: effects of network position and absorptive capacity on business unit innovation and performance," Academy of Management Journal, vol. 44, no. 5, pp. 996-1004, 2001.

[12] E. Giuliani and M. Bell, "The micro-determinants of mesolevel learning and innovation: evidence from a Chilean wine cluster," Research Policy, vol. 34, no. 1, pp. 47-68, 2005.

[13] S. Gao, K. Xu, and J. Yang, "Managerial ties, absorptive capacity, and innovation," Asia Pacific Journal of Management, vol. 25, no. 3, pp. 395-412, 2008.

[14] A. Escribano, A. Fosfuri, and J. A. Tribó, "Managing external knowledge flows: the moderating role of absorptive capacity," Research Policy, vol. 38, no. 1, pp. 96-105, 2009.

[15] Q. Meng, Y. Hang, and X. Chen, "User roles in virtual community of crowdsourcing for innovation: a case study of xiaomi MIUI in China," Tehnički Vjesnik, vol. 26, no. 5, pp. 1392-1399, 2019.

[16] S. Nambisan and R. A. Baron, "Virtual customer environments: testing a model of voluntary participation in value Co-creation activities," Journal of Product Innovation Management, vol. 26, no. 4, pp. 388-406, 2009.

[17] D. Mahr and A. Lievens, "Virtual lead user communities: drivers of knowledge creation for innovation," Research Policy, vol. 41, no. 1, pp. 167-177, 2012.

[18] M. Qin, H. Qiao, and L. Chen, "Online user contribution behavior in enterprise-hosted open innovation CommunitiesBased on complex adaptive system:an example of Chinese famous enterprise-hosted community," Management Review, vol. 27, no. 1, pp. 126-137, 2015.

[19] C. S. Dweck, "Motivational processes affecting learning," American Psychologist, vol. 41, no. 10, pp. 1040-1048, 1986.

[20] P. Chen and D. Zeng, "The impacts of network positions, knowledge base on firms' new product development performance," Management Review, vol. 31, no. 11, pp. 128-138, 2019.

[21] J. Xin, "Research on tacit knowledge sharing in organizational social networks from the perspective of structural holes," Information and Documentation(China), vol. 31, no. 1, pp. 32-36, 2012.

[22] Z. Li, Y. Wu, and C. Yu, "Knowledge subgroups in virtual communities based on affiliation," The Open Cybernetics \& Systemics Journal, vol. 9, no. 1, 2015.

[23] G. Khatwani and P. R. Srivastava, "Impact of information technology on information search channel selection for consumers," Journal of Organizational and End User Computing, vol. 30, no. 3, pp. 63-80, 2018.

[24] B. Ruhnau, "Eigenvector-centrality - a node-centrality?" Social Networks, vol. 22, no. 4, pp. 357-365, 2000.

[25] P. Bonacich, "Some unique properties of eigenvector centrality," Social Networks, vol. 29, no. 4, pp. 555-564, 2007.

[26] P. Howlader and K. S. Sudeep, "Degree centrality, eigenvector centrality and the relation between them in twitter," in Proceedings of the IEEE International Conference on Recent Trends in Electronics, pp. 678-682, Information \& Communication Technology, Bangalore, India, May 2016.

[27] R. S. Burt, "Reinforced structural holes," Social Networks, vol. 43, pp. 149-161, 2015.

[28] A. Zaheer and G. G. Bell, "Benefiting from network position: firm capabilities, structural holes, and performance," Strategic Management Journal, vol. 26, no. 9, pp. 809-825, 2005.

[29] M. Martinez, "Solver engagement in knowledge sharing in crowdsourcing communities: exploring the link to creativity," Research Policy, vol. 44, no. 8, pp. 1419-1430, 2015.

[30] S. E. Dahiyat, "An integrated model of knowledge acquisition and innovation: examining the mediation effects of knowledge integration and knowledge application," International Journal of Learning and Change, vol. 8, no. 2, pp. 101-135, 2015.

[31] G. D. C. Martín, "Knowledge management and innovation in knowledge-based and high-tech industrial markets: the role of openness and absorptive capacity," Industrial Marketing Management, vol. 47, pp. 143-146, 2015.

[32] H. T. W. Frankort, "When does knowledge acquisition in R\&D alliances increase new product development? The moderating roles of technological relatedness and productmarket competition," Research Policy, vol. 45, no. 1, pp. 291-302, 2016. 
[33] B. R. Koka and J. E. Prescott, "Strategic alliances as social capital: a multidimensional view," Strategic Management Journal, vol. 23, no. 9, pp. 795-816, 2002.

[34] M. Reinholt, T. Pedersen, and N. J. Foss, "Why a central network position isn't enough: the role of motivation and ability for knowledge sharing in employee networks," Academy of Management Journal, vol. 54, no. 6, pp. 1277-1297, 2011.

[35] G. Santoro, S. Bresciani, and A. Papa, "Collaborative modes with cultural and creative industries and innovation performance: the moderating role of heterogeneous sources of knowledge and absorptive capacity," Technovation, vol. 92-93, 2020.

[36] S. Moreira, A. Markus, and K. Laursen, "Knowledge diversity and coordination: the effect of intrafirm inventor task networks on absorption speed," Strategic Management Journal, vol. 39, no. 9, pp. 2517-2546, 2018.

[37] P. Djoko, P. Wahono, and Z. Puspitaningtyas, "The role of knowledge absorption in the mediation of the effect of social network on the competitive advantages of "batik" micro company"," Archives of Business Research (ABR), vol. 5, no. 12, 2017.

[38] J. Liu, Whole Network Analysis Lecture Notes: UCINET Software Practical Guide, Shanghai People's Publishing House, Shanghai, China, Third edition, 2019.

[39] K. G. Atuahene, S. F. Slater, and E. M. Olson, "The contingent value of responsive and proactive market orientations for new product program performance," Journal of Product Innovation Management, vol. 22, no. 6, pp. 464-482, 2005.

[40] R. S. Burt, Structural holes versus network closure as social capital, pp. 31-55, Routledge, Oxfordshire, UK, 2001, https://www. taylorfrancis.com/chapters/edit/10.4324/9781315129457-2/struc tural-holes-versus-network-closure-social-capital-ronald-burt.

[41] Q. Chen, Advanced Econometrics and Stata Application, Higher Education Press, Beijing, China, 2014.

[42] X. Liu, P. Zhang, X. Zhang et al., "Empirical study on impact of individual status on knowledge diffusion in scientific networks," Journal of Systems Management, vol. 23, no. 1, pp. 135-143, 2014.

[43] Z. Xiao and A. S. Tsui, "When brokers may not work: the cultural contingency of social capital in Chinese high-tech firms," Administrative Science Quarterly, vol. 52, no. 1, pp. 1-31, 2007.

[44] Z. Wen and B. Ye, "Analysis of mediation effect: method and model development," Advances in Psychological Science, vol. 22, no. 5, pp. 731-745, 2014.

[45] R. Agler and P. D. Boeck, "On the interpretation and use of mediation: multiple perspectives on mediation analysis," Frontiers in Psychology, vol. 8, 2017.

[46] E. V. Hippel, The Sources of Innovation, Das Summa Summarum Des Management, Berlin, Germany, pp. 111-120, 2007.

[47] A. Shahri, "How to engineer gamification: the consensus, the best practice and the grey areas," Journal of Organizational and End User Computing, vol. 31, no. 1, pp. 39-60, 2019. 